\title{
Combination of yeast antagonists and Acibenzolar-S-Methyl reduced the severity of Fusarium head blight of wheat incited by Fusarium graminearum sensu stricto
}

\author{
Sinegugu Precious N. Shude ${ }^{1}$, Nokwazi C. Mbili ${ }^{1}$ \& Kwasi S. Yobo ${ }^{1^{\star}}$ \\ Discipline of Plant Pathology, School of Agricultural, Earth and Environmental Sciences, University of KwaZulu-Natal, Private Bag X01, Scottsville, \\ Pietermaritzburg, 3209, Republic of South Africa
}

*Email: Yobok@ukzn.ac.za

OPEN ACCESS

\section{ARTICLE HISTORY}

Received: 14 August 2021

Accepted: 21 November 2021

Available online

Version 1.0 (Early Access): 25 December 2021 Version 2.0: 01 January 2022

\section{Check for updates}

\section{Additional information}

Peer review: Publisher thanks Sectional Editor and the other anonymous reviewers for their contribution to the peer review of this work.

Reprints \& permissions information is available at https://horizonepublishing.com/ journals/index.php/PST/open_access_policy

Publisher's Note: Horizon e-Publishing Group remains neutral with regard to jurisdictional claims in published maps and institutional affiliations.

Indexing: Plant Science Today, published by Horizon e-Publishing Group, is covered by Scopus, Web of Science, BIOSIS Previews, Clarivate Analytics, etc. See https://

horizonepublishing.com/journals/index.php/ PST/indexing_abstracting

Copyright: ( $)$ The Author(s). This is an openaccess article distributed under the terms of the Creative Commons Attribution License, which permits unrestricted use, distribution and reproduction in any medium, provided the original author and source are credited (https://creativecommons.org/licenses/ by/4.0/)

\section{CITE THIS ARTICLE}

Shude S P N, Mbili N C, Yobo K S. Combination of yeast antagonists and Acibenzolar-SMethyl reduced the severity of Fusarium head blight of wheat incited by Fusarium graminearum sensu stricto. Plant Science Today. 2022;9(1):198-205. https://doi.org/10.14719/ pst.1438

\begin{abstract}
The combination of yeast antagonists and Acibenzolar-S-Methyl (ASM) was tested against Fusarium graminearum on a spring wheat cultivar PAN3471. Two strains of Papiliotrema flavescens (Strains WL3 and WL6) and a strain of Pseudozyma sp. (MGO1) were combined with full strength ASM at anthesis, half strength ASM at anthesis and quarter strength ASM at late boot stages. The yeast and ASM treatments were applied prior to F. graminearum inoculation and disease progress was assessed over time. The combination of yeast and ASM treatments effectively reduced Fusarium Head Blight (FHB) severity and deoxynivalenol (DON) concentration compared to when the treatments were used alone. A positive correlation was observed between the Area Under Disease Progress Curve (AUDPC) and Percentage Seed Infection (PSI) $(r=0.44)$ whereas a negative correlation was observed between AUDPC and Hundred Seed Weight (HSW) $(r=-0.77)$ and PSI and HSW $\quad(r=-$ $0.44)$. The best combination treatment providing the highest reduction in final disease severity (41.83\%), high HSW and moderate PSI was $0.075 \mathrm{~g} / \mathrm{l}$ ASM at anthesis plus $P$. flavescens strain WL3. The highest DON reduction $(19.35 \%)$ was by the treatment $0.075 \mathrm{~g} / \mathrm{ASM}$ at anthesis plus $P$. flavescens strain WL6. The best treatment was P. flavescens combined with $0.075 \mathrm{~g} / \mathrm{l}$ ASM at anthesis. Although Pseudozyma sp. strain MGO1 did not provide the best FHB and DON reduction, its combination with ASM application improved disease control efficacy. To the best of our knowledge, this study presents the first report of the combination of $P$. flavescens and ASM in the management of FHB caused by $F$. graminearum in wheat plants.
\end{abstract}

\section{Keywords}

Biological control, induced resistance, Papiliotrema flavescens, Pseudozyma sp., mycotoxins, deoxynivalenol

\section{Introduction}

One of the major effects of Fusarium Head Blight (FHB) in crops is the production of mycotoxins in infected grains (1-3). These mycotoxins are a threat to human and animal health and have been reported to increase disease severity during infection by possibly disabling the plants' natural defence mechanisms $(2,4,5)$. FHB infection is accompanied by the production of Fusarium-Damaged Kernels (FDKs) which cannot be used as either food, feed or seed $(5,6)$. The mycotoxins that are produced by $F$. graminearum [teleomorph Gibberella zeae (Schwein.) Petch], a predominant causal agent of FHB, are deoxynivalenol (DON) (and its derivatives), nivalenol (NIV) (and its derivatives) and zearalenone (ZEA) $(5,7,8)$. Apart from DON being the 
least harmful type B trichothecene mycotoxin, it is the most frequently detected mycotoxin and thus an indicator for mycotoxin contamination in FHB-infected grains (3, 4, 9). Previous studies indicate that pre-harvest control of FHB infection and development is the most promising means of reducing mycotoxin contamination on grains (5, $6,10)$. This is because mycotoxin detoxification methods have limited efficacy on harvested grains and these methods have not yet been approved for use on grains with mycotoxin levels above acceptable limits (10).

Certain fungicides, such as triazole-based fungicides, have been used against FHB with reported efficacies (11-14). In resistance breeding programmes, some progress has been made which includes the identification of possible sources of resistance (such as the Chinese cultivar 'Sumai 3') (2, 5, 15). Although some FHB control efforts have shown potential in disease reduction, there are currently no registered fungicides or bio-fungicides, and no commercially available resistant wheat varieties in most parts of the world $(2,6,16)$. Current research into the control of FHB has been aimed at the use of natural antagonists, resistance breeding and integrated management (2, $5,6,14,17)$. These methods are of research interest since they address the issues associated with fungicide use which include chemical residues in/on food and the development of resistant pathogen strains (due to excessive use) $(2,4,18)$. Biological control of plant diseases has been studied over the years with reported efficacy. Its advantages include reduced environmental hazards (compared to chemical use), reduced likelihood of resistance development, and the production of durable plant protection (19). BCAs can be applied on plant residues (13), plant tissue (13), soil $(20,21)$ and/or seed. Soil treated with Trichoderma harzianum and $T$. viride increased shoot dry weight, root dry weight and grain yield in the control of Sclerotium rolfsii (22). On the same study, the two Trichoderma species were reported to promote plant health by normalizing peroxidase (POX), phenylalanine ammonia lyase (PAL) and catalase (CAT) post inoculation with $S$. rolfsii. Streptomyces sp. RC $87 \mathrm{~B}$ reduced $\mathrm{FHB}$ severity and DON by up to $39 \%$ and $85 \%$ respectively, on wheat during field trials (13). When applied on wheat stubble, Strptomyces sp. RC 87B reduced $F$. graminearum inoculum by at least $46 \% 90$ days post inoculation (13).

It has been suggested that the best way to manage FHB is through integrated control strategies $(11,15,23)$. Several studies on the incorporation of biological control agents (BCAs) in an integrated strategy for the control of FHB have been reported $(24,25)$. The co-culture of Cryptococcus flavescens $\mathrm{OH} 182.9$ and $C$. aureus $\mathrm{OH} 71.4$ significantly reduced FHB severity (by $32 \%$ on average) compared to individual applications (25). The integration of resistance inducers with BCAs in the management of $\mathrm{FHB}$ in wheat has been previously studied (26). However, this study reports for the first time the combination of Acibenzolar-S-Methyl (ASM) and yeast antagonists in an integrated management strategy of FHB caused by F. graminearum. The aim of this study was to test the efficacy of combining ASM with yeast antagonists for the reduction of FHB severity and DON contamination in wheat. The effectiveness of the combined treatments as against each of the treatments alone was measured using the following parameters: (i) measure disease severity, (ii) Hundred Seed Weight (HSW), (iii) Percentage Seed Infection (PSI) and (iv) mycotoxin concentration (DON and ZEA) in harvested grains.

\section{Materials and Methods}

\section{Planting and experimental design}

Sixty-five planting pots of $25 \mathrm{~cm}$ diameter were filled up to $90 \%$ capacity with composted pine bark potting medium. Thereafter, spring wheat five seeds [cultivar PAN3471 obtained from Pannar Seed (Pvt) Ltd, Greytown, Republic of South Africa] were sown at even spacing in each pot which constituted an experimental unit. The trial consisted of 16 treatments (Table 1) with five replicates each. A completely randomised design was used for this experiment. The

Table 1. The description of the 16 treatments designed for the integration trial which consists of Acibenzolar-S-Methyl (ASM) and biological control agent $(B C A)$ treatments.

\begin{tabular}{|c|c|c|}
\hline $\begin{array}{l}\text { Treat- } \\
\text { ment no. }\end{array}$ & $\begin{array}{l}\text { Treatment } \\
\text { name }\end{array}$ & Description \\
\hline 1 & ASM1 & $0.075 \mathrm{~g} / \mathrm{L} \mathrm{ASM}$ at anthesis (Feeke's 10.5.1) \\
\hline 2 & ASM2 & $0.019 \mathrm{~g} / \mathrm{L} \mathrm{ASM}$ at late boot stage (Feeke's 10) \\
\hline 3 & ASM3 & $0.0563 \mathrm{~g} / \mathrm{L}$ ASM at anthesis (Feeke's 10.5.1) \\
\hline 4 & BCA1 & Papiliotrema flavescens WL3 \\
\hline 5 & BCA2 & Papiliotrema flavescens WL6 \\
\hline 6 & $\mathrm{BCA} 3$ & Pseudozyma sp. MGO1 \\
\hline 7 & $\begin{array}{l}\text { ASM1+ } \\
\text { BCA1 }\end{array}$ & $\begin{array}{l}0.075 \mathrm{~g} / \mathrm{L} \text { ASM at anthesis (Feeke's 10.5.1) + } \\
\text { P. flavescens WL3 }\end{array}$ \\
\hline 8 & $\begin{array}{l}\text { ASM1+ } \\
\text { BCA2 }\end{array}$ & $\begin{array}{l}0.075 \mathrm{~g} / \mathrm{L} \text { ASM at anthesis (Feeke's 10.5.1) + } \\
\text { P. flavescens WL6 }\end{array}$ \\
\hline 9 & $\begin{array}{l}\text { ASM1+ } \\
\text { BCA3 }\end{array}$ & $\begin{array}{l}0.075 \mathrm{~g} / \mathrm{L} \text { ASM at anthesis (Feeke's 10.5.1) + } \\
\text { Pseudozyma sp. MGO1 }\end{array}$ \\
\hline 10 & $\begin{array}{l}\mathrm{ASM} 2+ \\
\mathrm{BCA} 1\end{array}$ & $\begin{array}{l}0.019 \mathrm{~g} / \mathrm{L} \text { ASM at late boot stage (Feeke's } 10)+ \\
\text { P. flavescens WL3 }\end{array}$ \\
\hline 11 & $\begin{array}{l}\mathrm{ASM} 2+ \\
\mathrm{BCA} 2\end{array}$ & $\begin{array}{l}0.019 \mathrm{~g} / \mathrm{L} \mathrm{ASM} \text { at late boot stage (Feeke's } 10)+ \\
\text { P. flavescens WL } 6\end{array}$ \\
\hline 12 & $\begin{array}{l}\text { ASM2+ } \\
\text { BCA3 }\end{array}$ & $\begin{array}{l}0.019 \mathrm{~g} / \mathrm{L} \text { ASM at late boot stage (Feeke's 10) + } \\
\text { Pseudozyma sp. MGO1 }\end{array}$ \\
\hline 13 & $\begin{array}{l}\text { ASM3+ } \\
\text { BCA1 }\end{array}$ & $\begin{array}{l}0.0563 \mathrm{~g} / \mathrm{L} \text { ASM at anthesis (Feeke's 10.5.1) + } \\
\text { P. flavescens WL3 }\end{array}$ \\
\hline 14 & $\begin{array}{l}\mathrm{ASM} 3+ \\
\mathrm{BCA} 2\end{array}$ & $\begin{array}{l}0.0563 \mathrm{~g} / \mathrm{L} \text { ASM at anthesis (Feeke's 10.5.1) + } \\
\text { P. flavescens WL6 }\end{array}$ \\
\hline 15 & $\begin{array}{l}\text { ASM3+ } \\
\text { BCA3 }\end{array}$ & $\begin{array}{l}0.0563 \mathrm{~g} / \mathrm{L} \mathrm{ASM} \text { at anthesis (Feeke's 10.5.1) + } \\
\text { Pseudozyma sp. MGO1 }\end{array}$ \\
\hline 16 & Control & No ASM and no yeast antagonist \\
\hline
\end{tabular}

Key: Feeke's 10 and Feeke's 10.5.1 are wheat growth stages presented by the Feeke's scale (28).

pots were placed in a growing area with insect netting (approximately 15\% shading) and a drip irrigation system was used where each pot received water for 2 mins four times a day. Osmocote Exact Mini 5-6 M 15-3.9-9.1 + 1.2 Mg + TE [supplied by Greenhouse products (Pvt) Ltd, Helderkruin, Republic of South Africa (RSA)], an ammonium based slow-release fertilizer, was applied in each pot at a rate of $2.5 \mathrm{~g} / \mathrm{l}$ of potting media. 


\section{Inoculum preparation}

A F. graminearum (strain F20) conidia suspension previously stored at $-80^{\circ} \mathrm{C}$, was thawed under a laminar flow cabinet at ambient temperature. This strain was obtained from the Discipline of Plant Pathology stock culture laboratory, University of KwaZulu-Natal, Pietermaritzburg, South Africa. The $F$. graminearum strain was previously isolated from infected wheat heads in a wheat cultivation field. Conidia were then streaked out onto fresh potato dextrose agar (PDA) plates and incubated at $25^{\circ} \mathrm{C}$ for 5 days. Thereafter, the culture was subcultured by cutting out a $1 \mathrm{~mm}^{3}$ agar plug from the actively growing edges of the mycelia and then placed faced down at the centre of a fresh PDA plate. This was repeated on 20 PDA plates and the plates were incubated at $25^{\circ} \mathrm{C}$ for 7 days. Thereafter, the plates were placed under ultraviolet-A (UVA) light (360 $\mathrm{nm}$ wavelength) for 14 days to induce fungal sporulation.

The yeast strains Papiliotrema flavescens [strains WL3 and WL6, previously isolated from wheat (Triticum aestivum L.) leaves] and Pseudozyma sp. [strain MGO1 previously isolated from Mondo grass (Ophiopogon japonicus (L.f.) Ker-Gaw) leaves] with proven efficacy against $F$. graminearum in vitro (27) were used in this study. These strains had been identified by Inqaba Biotechnological industries (Pvt) Ltd (Muckleneuk, Pretoria, RSA) using Internal Transcribed Spacers (ITS) sequencing and molecular identification. The yeast strains were streaked out from their respective stock solutions (previously stored at $-80^{\circ} \mathrm{C}$ ) onto fresh PDA plates with 10 replicates each and thereafter incubated at $25{ }^{\circ} \mathrm{C}$ for 5 days. Thereafter, $4 \mathrm{ml}$ of sterile distilled water was pipetted onto each plate using a micropipette under aseptic conditions. Using a flamesterilized L- bent glass rod, the culture was suspended in the water by lightly rubbing the surface of the plate. The aliquot was decanted into a sterile and appropriately labelled conical flask. This was repeated for all the plates resulting in three flasks containing each yeast isolate.

Conidial suspensions of F. graminearum $\mathrm{F} 20$ were prepared as above. The aliquot was transferred into a sterile Schott bottle which was vigorously shaken to allow the suspension of conidia in the solution. The aliquot was sieved through a sterile cheesecloth to remove mycelia and agar debris. Thereafter, the conidial concentration was adjusted to $1 \times 10^{5}$ conidia/ml using a haemocytometer and then made up to $10 \mathrm{l}$. The spore concentrations of each of the 3 yeasts were adjusted to $1 \times 10^{7}$ spores $/ \mathrm{ml}$ and the solutions were made up to $4 \mathrm{l}$ each.

\section{Treatments application}

Acibenzolar-S-Methyl (ASM) granules were purchased from Syngenta (Pvt) Ltd, Halfway house, Johannesburg, RSA. To prepare ASM concentrations, beakers were filled with tap water and placed on a bench top for an hour to allow the release of excess chlorine. ASM granules were weighed ( $0.019 \mathrm{~g}, 0.0563 \mathrm{~g}$ and $0.075 \mathrm{~g})$ and each amount separately dissolved in $1 \mathrm{~L}$ of the tap water. The ASM solutions were transferred to previously cleaned and appropriately labelled 1 I pump spray bottles. With the nozzle adjusted to emit a fine mist, the plants were sprayed with the appropri- ate ASM solutions until runoff at the appropriate growth stages (Table 1).

Wheat heads were sprayed with the appropriate yeast spore suspensions until runoff according to the assigned treatments presented in Table 1 . In all in vivo inoculations, plants of the same treatment were sprayed separately, away from the other plants to prevent spray drift. The heads were then covered with perforated, light-weight plastic bags for $24 \mathrm{hrs}$. to encourage humidity. Forty-eight hrs after yeast inoculation, the wheat heads were sprayed with conidial suspensions of $F$. graminearum until runoff and thereafter covered with the same plastic bags for 24 hrs to encourage disease development. Yeast and F. graminearum inoculations were each performed once. Disease severity was measured using a visual scale originally described by (29) and disease ratings were recorded in intervals over time. The experiment was repeated once.

When the plants had a golden-brown appearance and had reached maturity, wheat heads were cut off from the straws and put in appropriately labelled collection bags according to treatment replicates. Harvested grains were placed in a ventilating oven set at $55^{\circ} \mathrm{C}$ for a period of 4 days. During this period, the bags were constantly monitored and shuffled to prevent heat damage of the grains. Thereafter, the wheat heads were threshed, and the seeds were transferred into appropriately labelled envelopes. These were stored in a cold room set at $4^{\circ} \mathrm{C}$ for further experiments.

HSW and PSI were determined per treatment replicate for the 2 experiments. For the PSI, the seeds were surface sterilized, cultured on freshly prepared PDA plates and incubated at $25^{\circ} \mathrm{C}$ for 4 days. Since each treatment had 5 replicates, each replicate had 3 plates which each had 15 seeds. The experiment was repeated once resulting in 30 plates per treatment. The number of Fusarium-infected seeds per plate was recorded and used to calculate the PSI using the following formula:

\section{Percentage Seed Infection $\left(\right.$ PSI) $=\frac{\text { No. of infected seeds }}{\text { Total seeds plated }} \times 100$}

\section{Mycotoxin analysis}

The target mycotoxins were DON and ZEA since they are the most prevalent mycotoxins in FHB infections. The roQ ${ }^{\mathrm{TM}}$ QuEChERS kits KSO-8909 and KSO-9507 were used for sample extraction and dispersive Solid Phase Extraction (dSPE) respectively. These were purchased from Separations (Pvt) Ltd, Johannesburg, RSA. Mycotoxin extraction was performed according to (30), with modifications. Wheat seeds from the 2 experiments were pooled according to treatments for mycotoxin analysis. For each sample, the seeds were ground into fine powder using a Mikro-FeinmuhleCullati (MFC) plant grinder in the Plant Pathology seeds laboratory. A 5 g subsample was added into a $50 \mathrm{ml}$ roQ QuEChERS extraction tube along with the following reagents: Milli-Q water $(10 \mathrm{ml})$, acetonitrile with $5 \%$ formic acid $(10 \mathrm{ml})$ and the contents of the roQ QuEChERS extraction packet (KSO-8909) which consisted of $4.0 \mathrm{~g} \mathrm{MgSO}_{4}, 1.0$ $\mathrm{g} \mathrm{NaCl}, 1.0 \mathrm{~g} \mathrm{SCTD}$ and $0.5 \mathrm{~g}$ SCDS (30). 
The tube was shaken for 1 min by hand and then centrifuged at $4000 \mathrm{rpm}(3000 \mathrm{~g})$ for 5 mins (Beckman Coulter, Avanti J-26 XPI centrigufe) (30). Six $\mathrm{ml}(6 \mathrm{ml})$ of the supernatant were transferred into a roQ QuEChERS $15 \mathrm{ml}$ centrifuge tube (KSO-9507) containing $900 \mathrm{mg} \mathrm{MgSO}_{4}$ and $150 \mathrm{mg}$ primary secondary amine (PSA) (30). The tube was shaken by hand for 30 secs and then centrifuged as above (30). Thereafter, $1 \mathrm{ml}$ of the supernatant was filtered through a $0.45 \mu \mathrm{m}$ pore filter and transferred into a $1.5 \mathrm{ml}$ autosampler vial (all purchased from Separations (Pvt) Ltd, Johannesburg, Republic of South Africa) (30). This was repeated for all the samples and the vials were left open in a laminar flow cabinet overnight to dry.

The samples were analysed for the quantification of DON and ZEA using High Performance Liquid Chromatography (HPLC) (30). The HPLC system consisted of an LC-2030 pump connected to an LC-2030/2040 PDA detector, LC-2030 controller and LC-2030 autosampler. Chromatographic separations were performed on a Kinetex ${ }^{\circ}$ $5 \mu \mathrm{m}$ Biphenyl 100A LC Column $(100 \times 2.1 \mathrm{~mm})$ connected to a guard column SecurityGuard ${ }^{\mathrm{TM}}$ filled with the same phase (2.1 to $4.6 \mathrm{~mm}$ ) (all purchased from Separations (Pvt) Ltd, Johannesburg, Republic of South Africa). The mobile phase consisted of aqueous $5 \mathrm{Mm}$ ammonium acetate with $0.1 \%$ acetic acid, $5 \mathrm{mM}$ ammonium acetate in methanol with $0.1 \%$ acetic acid, acetonitrile and Milli-Q water. The flow rate was $0.20 \mathrm{ml} / \mathrm{min}$ and the injection volume was $50 \mu \mathrm{l}$. The retention times for DON and ZEA were 2.563 and 10.193 mins respectively. Quantification was relative to external standards of $1-8 \mu \mathrm{g} / \mathrm{ml}$ in acetonitrile. Three quantification readings were conducted per sample.

\section{Data analysis}

HSW, PSI and disease severity data obtained were checked for homogeneity within the repeated trials and the data were thereafter pooled. Disease severity data was used to calculate the Area Under the Disease Progress Curve (AUDPC) for all treatments (31) before subjected to ANOVA. If the ANOVA was significant $(P \leq 0.05)$, the means were separated using the Duncan's Multiple Range Test (DMRT) at 5\% significance level using SAS software Version 9.4 (32). Pairwise correlations were determined between AUDPC, HSW and PSI for the pooled data using the Spearman's correlation test (32). The rate of disease progress ( $r$ ) was calculated using the Vanderplanks' logistic equation (33) expressed below:

$$
r=\frac{1}{t_{2}-t_{1}}\left[\left(\ln \frac{x_{2}}{1-x_{2}}\right)-\left(\ln \frac{x_{1}}{1-x_{1}}\right)\right]
$$

where; $t_{1}=$ initial day of rating; $t_{1}=$ final day of rating; $x_{1}=$ initial disease value; $x_{2}=$ final disease value.

\section{Results}

\section{Disease severity and seed infection studies}

The $0.075 \mathrm{~g} / \mathrm{l}$ ASM treatment at anthesis plus $P$. flavescens WL6 had the lowest disease severity rating in all rating days and thus the lowest final average disease severity (50.92\%) compared to the control (87.53\%) (Table 2). This means that the number of infected spikes for the treatment $0.075 \mathrm{~g} / \mathrm{L}$ ASM at anthesis plus P. flavescens WL 6 were significantly less than those for the control treatment. The control treatment had the highest average disease severity

Table 2. The average Fusarium Head Blight (FHB) severities of the 16 treatments throughout the disease rating days

\begin{tabular}{|c|c|c|c|c|c|c|c|c|c|}
\hline \multirow{2}{*}{\multicolumn{2}{|c|}{$\begin{array}{l}\text { Treatment } \\
\text { No. }\end{array}$}} & \multicolumn{8}{|c|}{ Number of days (Disease Rating days) } \\
\hline & & 0 & 15 & 19 & 22 & 25 & 29 & 33 & 43 \\
\hline 1 & $0.075 \mathrm{~g} / \mathrm{L}$ ASM at anthesis & 0 & 22.83 & 31.75 & 36.75 & 41.33 & 46.13 & 51.75 & 52.38 \\
\hline 2 & $0.019 \mathrm{~g} / \mathrm{L} \mathrm{ASM}$ at late boot stage & 0 & 27.58 & 38.62 & 44.46 & 56.33 & 63.63 & 68.31 & 73.94 \\
\hline 3 & $0.0563 \mathrm{~g} / \mathrm{L} \mathrm{ASM}$ at anthesis & 0 & 31.83 & 39.25 & 44.88 & 54.25 & 56.75 & 60.08 & 64.88 \\
\hline 4 & P. flavescens WL3 & 0 & 34.04 & 44.88 & 51.54 & 58.42 & 68.63 & 70.71 & 73.00 \\
\hline 5 & P. flavescens WL6 & 0 & 20.75 & 34.04 & 38.88 & 44.50 & 49.46 & 54.15 & 56.54 \\
\hline 6 & Pseudozyma sp. MGO1 & 0 & 15.29 & 37.38 & 42.38 & 49.87 & 55.71 & 62.58 & 69.35 \\
\hline 7 & $0.075 \mathrm{~g} / \mathrm{L}$ ASM at anthesis plus $P$. flavescens WL3 & 0 & 21.21 & 31.96 & 39.25 & 47.17 & 54.88 & 59.36 & 63.10 \\
\hline 8 & $0.075 \mathrm{~g} / \mathrm{L}$ ASM at anthesis plus P. flavescens WL6 & 0 & 10.80 & 24.08 & 27.71 & 36.33 & 41.96 & 50.08 & 50.92 \\
\hline 9 & $0.075 \mathrm{~g} / \mathrm{L}$ ASM at anthesis plus Pseudozyma sp. MGO1 & 0 & 16.29 & 30.42 & 36.96 & 44.15 & 48.83 & 57.79 & 59.88 \\
\hline 10 & $0.019 \mathrm{~g} / \mathrm{L}$ ASM at late boot stage plus P. flavescens WL3 & 0 & 22.50 & 32.38 & 39.67 & 47.58 & 51.54 & 56.96 & 62.38 \\
\hline 12 & $0.019 \mathrm{~g} / \mathrm{L} \mathrm{ASM}$ at late boot stage plus Pseudozyma sp. MGO1 & 0 & 19.17 & 34.88 & 38.00 & 49.46 & 53.42 & 59.25 & 67.27 \\
\hline 13 & $0.0563 \mathrm{~g} / \mathrm{L}$ ASM at anthesis plus P. flavescens WL3 & 0 & 14.63 & 27.04 & 33.42 & 42.58 & 48.00 & 50.50 & 59.46 \\
\hline 14 & $0.0563 \mathrm{~g} / \mathrm{L}$ ASM at anthesis plus P. flavescens WL6 & 0 & 15.38 & 28.63 & 38.83 & 47.38 & 52.63 & 55.71 & 60.92 \\
\hline 15 & $0.0563 \mathrm{~g} / \mathrm{L} \mathrm{ASM}$ at anthesis plus Pseudozyma sp. MGO1 & 0 & 22.48 & 36.54 & 43.21 & 55.92 & 61.13 & 63.63 & 69.88 \\
\hline 16 & Control & 0 & 49.92 & 60.48 & 66.69 & 74.62 & 79.88 & 83.00 & 87.53 \\
\hline \multicolumn{2}{|c|}{ Effects } & \multicolumn{4}{|c|}{ F-value } & \multicolumn{4}{|c|}{ P-value } \\
\hline \multicolumn{2}{|c|}{ Treatments } & \multicolumn{4}{|c|}{30.5} & \multicolumn{4}{|c|}{0.0001} \\
\hline \multicolumn{2}{|c|}{ Time (Days) } & \multicolumn{4}{|c|}{492.43} & \multicolumn{4}{|c|}{0.0001} \\
\hline \multicolumn{2}{|c|}{ Treatments`Time (Days) } & \multicolumn{4}{|c|}{0.95} & \multicolumn{4}{|c|}{0.633} \\
\hline \multicolumn{2}{|l|}{$\% \mathrm{CV}$} & \multicolumn{8}{|c|}{26.7} \\
\hline
\end{tabular}


in all rating days (Table 2 ).

There were significant differences between the treatments for the AUDPC, HSW and PSI at $p \leq 0.0006, p \leq$ 0.0001 and $p \leq 0.06$ respectively (Table 3 ). The lowest AUDPC and PSI values were observed for treatments 0.075 $\mathrm{g} / \mathrm{ASM}$ at anthesis plus P. flavescens WL6 and $0.075 \mathrm{~g} / \mathrm{l}$ ASM at anthesis plus Pseudozyma sp. MGO1 respectively. The highest HSW was observed for the treatment $0.0563 \mathrm{~g} / \mathrm{l}$ ASM at anthesis plus $P$. flavescens WL3. The PSI values of 8 out of 15 treatments were not significantly different from nificant at $p=0.0002$. A strong and moderate negative correlation was observed between AUDPC and HSW ( $r=-0.77$ ) and PSI and HSW ( $r=-0.44)$ respectively. These were significant at $p<0.0001$ and $p=0.0003$, respectively. The highest negative correlation was observed between AUDPC and HSW.

\section{Mycotoxin analysis}

A reduction of up to $19.45 \%$ in DON concentration was obtained and this was by the treatment $0.075 \mathrm{~g} / \mathrm{l} \mathrm{ASM}$ at anthesis plus $P$. flavescens WL3 ( Table 5). Although statistical-

Table 3. The average Area Under the Disease Progress Curve (AUDPC), average Hundred Seed Weight (HSW) (g), average Percentage Seed Infection (PSI) (\%) and rate of disease progress ( $r$ ) for the 16 treatments tested against Fusarium Head Blight (FHB) in vivo

\begin{tabular}{|c|c|c|c|c|}
\hline Treatment & AUDPC & Average HSW (g) & Average PSI (\%) & $(\mathbf{r})$ \\
\hline $0.075 \mathrm{~g} / \mathrm{L} \mathrm{ASM}$ at anthesis & $1113.27 \pm 122.90^{\text {cd }}$ & $2.96 \pm 0.23^{\mathrm{ab}}$ & $39.58 \pm 12.02^{\mathrm{bc}}$ & 0.06 \\
\hline $0.0563 \mathrm{~g} / \mathrm{L} \mathrm{ASM}$ at anthesis & $1389.00 \pm 182.12^{\mathrm{bc}}$ & $2.81 \pm 0.24^{\mathrm{ab}}$ & $54.17 \pm 5.13^{\mathrm{abc}}$ & 0.05 \\
\hline Papiliotrema flavescens WL3 & $1579.20 \pm 60.66^{b}$ & $1.86 \pm 0.21^{c}$ & $52.78 \pm 4.39 \mathrm{abc}$ & 0.06 \\
\hline Papiliotrema flavescens WL6 & $1158.57 \pm 118.53^{\mathrm{bcd}}$ & $2.92 \pm 0.23^{\mathrm{ab}}$ & $34.72 \pm 1.79^{\mathrm{bc}}$ & 0.07 \\
\hline Pseudozyma sp. MGO1 & $1268.36 \pm 111.00^{\mathrm{bcd}}$ & $2.79 \pm 0.23^{\mathrm{ab}}$ & $56.94 \pm 8.67^{\mathrm{abc}}$ & 0.10 \\
\hline $0.075 \mathrm{~g} / \mathrm{L} \mathrm{ASM}$ at anthesis plus $P$. flavescens WL3 & $1237.34 \pm 167.87^{\mathrm{bcd}}$ & $2.85 \pm 0.29^{\mathrm{ab}}$ & $37.50 \pm 8.06^{b c}$ & 0.08 \\
\hline $0.075 \mathrm{~g} / \mathrm{L} \mathrm{ASM}$ at anthesis plus $P$. flavescens WL6 & $936.16 \pm 182.93^{d}$ & $3.32 \pm 0.22^{\mathrm{ab}}$ & $49.31 \pm 2.63^{\mathrm{abc}}$ & 0.09 \\
\hline $0.019 \mathrm{~g} / \mathrm{L}$ ASM at late boot stage plus P. flavescens WL3 & $1223.48 \pm 88.46^{\mathrm{bcd}}$ & $3.06 \pm 0.10^{\mathrm{ab}}$ & $51.39 \pm 10.42^{\mathrm{abc}}$ & 0.07 \\
\hline $0.019 \mathrm{~g} / \mathrm{L}$ ASM at late boot stage plus P. flavescens WL6 & $1208.75 \pm 146.97^{\mathrm{bcd}}$ & $3.11 \pm 0.22^{\mathrm{ab}}$ & $41.67 \pm 9.00^{\mathrm{bc}}$ & 0.06 \\
\hline $0.019 \mathrm{~g} / \mathrm{L}$ ASM at late boot stage plus Pseudozyma sp. MGO1 & $1244.82 \pm 134.54^{\mathrm{bcd}}$ & $3.01 \pm 0.22^{\mathrm{ab}}$ & $50.69 \pm 2.86^{\mathrm{abc}}$ & 0.09 \\
\hline $0.0563 \mathrm{~g} / \mathrm{L}$ ASM at anthesis plus $P$. flavescens WL3 & $1060.53 \pm 156.16^{\mathrm{cd}}$ & $3.41 \pm 0.26^{\mathrm{a}}$ & $36.11 \pm 11.05^{\mathrm{bc}}$ & 0.09 \\
\hline $0.0563 \mathrm{~g} / \mathrm{L}$ ASM at anthesis plus $P$. flavescens WL 6 & $1146.89 \pm 85.97^{\mathrm{bcd}}$ & $3.34 \pm 0.18^{\mathrm{ab}}$ & $50.69 \pm 9.17^{\mathrm{abc}}$ & 0.08 \\
\hline $0.0563 \mathrm{~g} / \mathrm{L}$ ASM at anthesis plus Pseudozyma sp. MGO1 & $1364.83 \pm 124.09^{\mathrm{bcd}}$ & $3.01 \pm 0.13^{\mathrm{ab}}$ & $44.44 \pm 4.09^{\mathrm{bc}}$ & 0.08 \\
\hline Control & $1964.98 \pm 97.08^{\mathrm{a}}$ & $1.77 \pm 0.23^{c}$ & $72.92 \pm 6.84^{\mathrm{a}}$ & 0.07 \\
\hline F value & 3.42 & 4.30 & 1.82 & \\
\hline$P$ value & 0.0006 & $<0.0001$ & 0.06 & \\
\hline
\end{tabular}

Values followed by the same superscript letter are statistically identical

the control (Table 3). As a result, some treatments with low AUDPC and HSW values were associated with high PSI values. An example of this was $0.075 \mathrm{~g} / \mathrm{l}$ ASM at anthesis plus $P$. flavescens WL6, which had the lowest AUDPC units, the third highest HSW and a below-average PSI that was not significantly different from the control. The control had the highest AUDPC units, lowest HSW and highest PSI. The highest rate of disease progress ( $r$ ) was observed for Pseudozyma sp. MGO1 and the lowest for $0.0563 \mathrm{~g} / \mathrm{l} \mathrm{ASM}$ at anthesis (Table 3). However, there was not much difference in the rate of disease progress between treatments and thus statistical analysis was omitted.

\section{Correlation between AUDPC, HSW and PSI}

Significant correlations were observed for all pairwise combinations (Table 4). A moderate positive correlation was observed between AUDPC and PSI $(r=0.44)$ which was sig-
Table 4. Pairwise correlation between the Area Under the Disease Progress Curve (AUDPC), Hundred Seed Weight (HSW) and Percentage Seed Infection (PSI) for the 16 treatments tested against Fusarium Head Blight.

\begin{tabular}{lccc}
\hline & AUDPC & HSW & PSI \\
\hline AUDPC & 1 & $-0.77^{\star}$ & $0.44^{\star \star}$ \\
HSW & & 1 & $-0.44^{\star \star \star}$ \\
PSI & & & 1 \\
\hline
\end{tabular}

Key: $\left({ }^{\star}\right)=p<0.0001 ;\left(^{\star \star}\right)=p=0.0002 ;\left(^{\star \star \star}\right)=p=0.0003$

ly similar to the DON concentration of the control, the other treatments with low DON concentrations were $0.075 \mathrm{~g} / \mathrm{l}$ ASM at anthesis and $0.075 \mathrm{~g} / \mathrm{l} \mathrm{ASM}$ at anthesis plus $P$. flavescens WL6 respectively. The treatment $0.019 \mathrm{~g} / \mathrm{l} \mathrm{ASM}$ at late boot stage was the only treatment that had a DON concentration higher than that of the control. ZEA was not detected in all tested treatments and the control, as indicated 
Table 5. Concentrations of deoxynivalenol (DON) and zearalenone (ZEA) in harvested grains for the 15 treatments compared to the control.

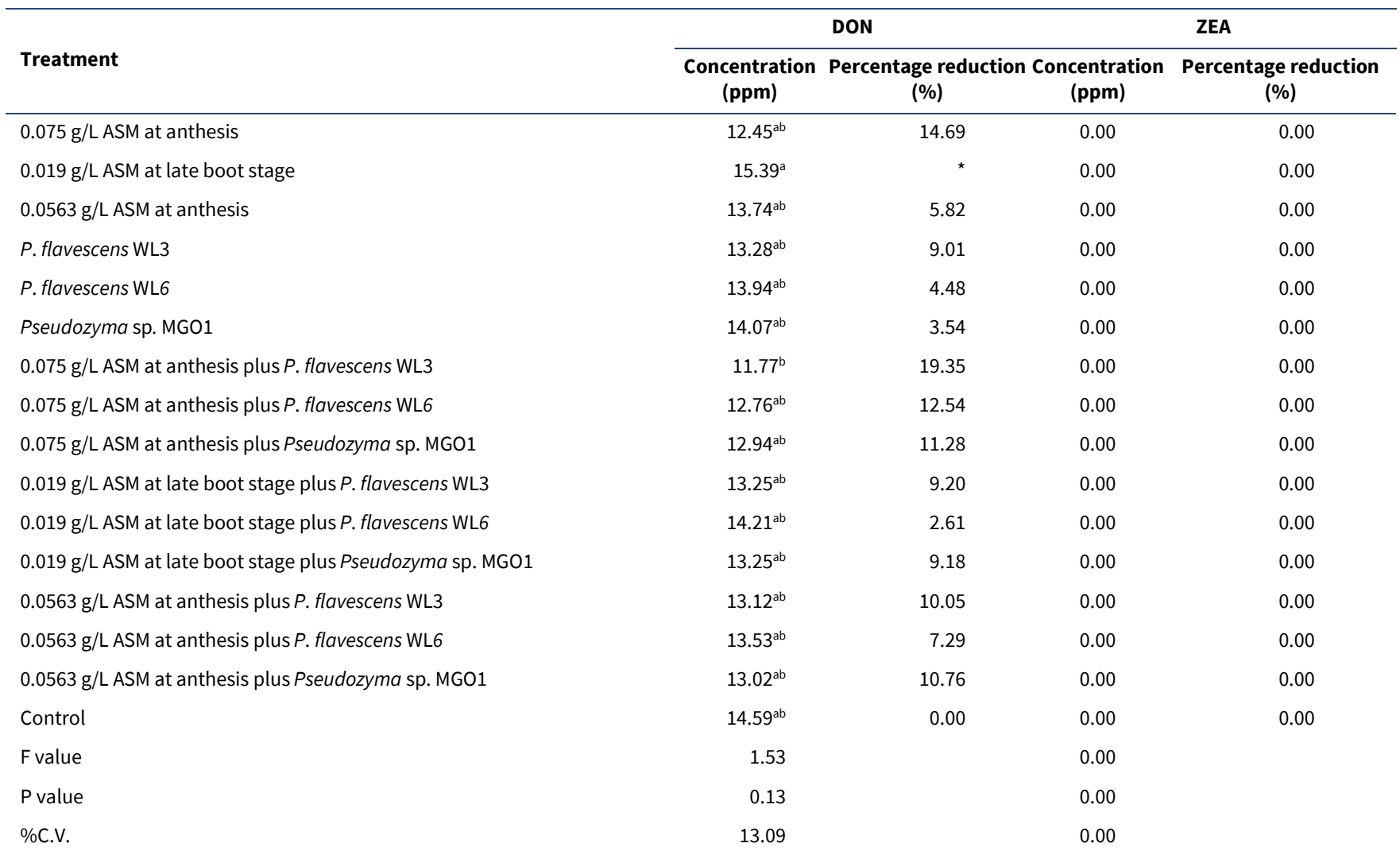

Key: $\left(^{\star}\right)=$ values less than zero (negative values) indicating an increase in DON concentration compared to the control. Values followed by the same superscript letter are statistically identical

by $0.00 \mathrm{ppm}$ in Table 5 .

\section{Discussion}

In this study, we demonstrated that the combination of a plant defence inducer (ASM) with yeast antagoist reduced the severity of FHB and DON concentration in wheat. There is limited research on the integration of plant defence inducers with yeast antagonists in the management of $\mathrm{F}$. graminearum in wheat. However, our results reveal good potential for FHB and DON reduction in wheat. When ASM was applied alone, the treatment $0.075 \mathrm{~g} / \mathrm{l} \mathrm{ASM}$ at anthesis had the lowest AUDPC units (1113.27), highest HSW (2.96 g) and the lowest DON concentration (12.45 ppm). When the biocontrol agents were applied alone, the treatment $P$. flavescens WL6 had the lowest AUDPC units (1158.57) and highest HSW $(2.92 \mathrm{~g})$, but $P$. flavescens WL3 had the lowest DON concentration (13.28 ppm). These treatments were previously tested prior to the current experiment (27) where their potential was studied. Although there is not much literature on the study of ASM for FHB control, ASM has been tested on other plant pathogens $(34,35)$. In a study to test the effect of ASM against Botrytis cinera on table grapes, ASM reduced the incidence of gray mold by up to $85 \%$ (34). Yeast biocontrol agents such as Cryptococcus flavescens $\mathrm{OH} 182.9$ have been studied and reported to effectively reduce FHB and DON concentrations in wheat (24-26).

The integration of ASM and biocontrol agents improved FHB reduction compared to when the treatments were applied alone. The best integration treatments providing the highest FHB and DON reduction were $0.075 \mathrm{~g} /$
I ASM at anthesis plus P. flavescens WL6 (41.83\%) and 0.075 g/l ASM at anthesis plus $P$. flavescens WL3 (19.35\%) respectively. Moreover, the treatment $0.075 \mathrm{~g} / \mathrm{l} \mathrm{ASM}$ at anthesis plus $P$. flavescens WL 6 had the highest reduction in AUDPC units (52.91\%), high DON reduction (12.54\%), high HSW (3.32 g) and a PSI below 50\%. It is important to note that the best integration treatments were comprised of treatments that performed best amongst those applied alone, which was expected. In another study, the combination of 4 resistance inducers with the yeast antagonist Cryptococcus flavescens $\mathrm{OH} 182.9$ did not significantly reduce FHB severity compared to when applied alone (24). However, lowest FHB severity values were often associated with integrated treatments (24). Our study, therefore, is the first to report effective reduction of FHB and DON in wheat following the integration of ASM treatments and yeast biocontrol agents.

An increase in FHB severity is accompanied by an increase in Fusarium-infected kernels and a reduction in seed weight $(4,36)$. Similar correlations were also observed in our study thus aiding to the efficacy of these treatments in FHB management. Although majority the PSI values in our study were not significantly different to that of the control, the PSI of the tested treatments could potentially decrease with higher treatment application doses or integration with postharvest control methods. Pseudozyma sp. MGO1, which was isolated from the weed plant Ophiopogon japonicus (Mondo grass), although did not provide the best FHB and DON reduction compared to $P$. flavescens WL 3 and P. flavescens WL6 treatments, the combination with ASM application resulted in increased efficacy. The treatment $0.075 \mathrm{~g} / \mathrm{l} \mathrm{ASM}$ at anthesis plus Pseudozyma sp. MGO1 was the best treatment amongst those treated with Pseudozy- 
ma sp. MGO1, providing a high DON reduction of $11.28 \%$ compared to other treatments. $O$. japonicus is a traditional Chinese medicinal plant with antifungal activities. There is currently no literature available on its antifungal properties being tested against $F$. graminearum. Our previous study (27) contains in vitro and in vivo screening experiments on the antifungal effect of yeast isolates (such as MGO1) isolated from 0 . japonicus against $F$. graminearum. Therefore, this is novel work which shows potential and requires more research.

Although the two $P$. flavescens strains belong to the same species, the differences in their efficacies against $F$. graminearum shows that they could be different strains. Nevertheless, the combinations of the P. flavescens WL6 with $0.075 \mathrm{~g} / \mathrm{l}$ ASM at anthesis was the overall best treatment in this study. Moreover, further research on the determination of the best inoculum dosage, frequency of appli- 3 . cation is required and could help improve the efficacy and reliability of the $P$. flavescens strains. Other studies in the control of plant diseases include testing ASM concentrations higher than the ones used in this study $(34,35)$. Therefore, future research can be aimed at determining the efficacy of higher ASM concentrations in the control of FHB of wheat as well as the physiological effects of the treatments on the wheat plant.

\section{Conclusion}

This study provides extensive research into the efficacy of Acibenzolar-S-Methyl (ASM) in the integrated control of Fusarium Head Blight (FHB) incited by $F$. graminearum in wheat plants. The combination of ASM and the $P$. flavescens strains provided the best FHB and deoxynivalenol (DON) reduction compared to when either were applied alone. The highest reduction in final FHB severity and DON concentration was observed where $0.075 \mathrm{~g} / \mathrm{l}$ ASM was applied at anthesis in combination with P. flavescens strains WL6 and WL3 respectively. To the best of our knowledge, this study presents the first report of $P$. flavescens strains as combination treatments with ASM in the management of FHB caused by $F$. graminearum in wheat plants. Field studies are essential to determine the efficacy of combined use of ASM and the $P$. flavescens strains in environments similar to those present in commercial wheat cultivation systems.

\section{Acknowledgements}

This study was funded by the University of KwaZulu-Natal Capacity Development Programme (UCDP), South Africa. The authors are also grateful to the National Research Foundation (NRF) of South Africa for student bursary.

\section{Authors contributions}

SS carried out the work and wrote the initial draft of the manuscript, implemented the comments after editing and revised the manuscript. NM - student co-supervision, funding acquisition and proof-reading of the final draft. KSY student supervision, project leadership and management, funding acquisition and editing of manuscript.

\section{Compliance with ethical standards}

Conflict of interest: Authors do not have any conflict of interests to declare.

Ethical issues: None.

\section{References}

1. Brown NA, Bass C, Baldwin TK, Chen H, Massot F, Carion PWC, Urban M, Van deMeene AML, Hammond-Kosack KE.. Characterisation of the Fusarium graminearum-wheat floral interaction. J Pathog. 2011;Article ID $626345 . \quad$ https:// doi.org/10.4061/2011/626345.

2. Dweba CC, Figlan S, Shimelis HA, Motaung TE, Sydenham S, Mwadzingeni L, Tsilo TJ. Fusarium head blight of wheat: Pathogenesis and control strategies. Crop Prot. 2017;91:114-22. https://doi.org/10.1016/j.cropro.2016.10.002

3. Lenc L. Fusarium head blight (FHB) and Fusarium populations in grain of winter wheat grown in different cultivation systems. J Plant Prot Res. 2015;55:94-109. https://doi.org/10.1515/jppr-2015 $-0013$

Gilbert J, Haber S. Overview of some recent research developments in Fusarium head blight of wheat. Can J Plant Pathol. 2013;35:149-74. https://doi.org/10.1080/07060661.2013.772921

5. Wegulo SN, Baenziger PS, Hernandez Nopsa J, Bockus WW, Hallen-Adams H. Management of Fusarium head blight of wheat and barley. Crop Prot. 2015;73:100-07. https://doi.org/10.1016/ j.cropro.2015.02.025

6. Schoeman A, Greyling-Joubert SM. Gibberella on maize, sorghum and wheat. Grain SA. [Internet] 2017 [cited 2017 Jul 7]. Available from: https://www.grainsa.co.za/gibberella-on-maize, -sorghum-and-wheat.

7. Boutigny AL, Beukes I, Viljoen A. Head blight of barley in South Africa is caused by Fusarium graminearum with a 15-adon chemotype. J Plant Pathol. 2011;93:321-29. https:// doi.org/10.4454/JPP.V9312.1186

8. Nielsen LK, Cook DJ, Edwards SG, Ray RV. The prevalence and impact of Fusarium head blight pathogens and mycotoxins on malting barley quality in UK. Int J Food Microbiol. 2014;179:3849. https://doi.org/10.1016/j.ijfoodmicro.2014.03.023

9. Matny O. Fusarium Head Blight and Crown Rot on wheat and barley: losses and health risks. Adv Plants Agric Res. 2015;2:2-7. https://doi.org/10.15406/apar.2015.02.00039

10. Jard G, Liboz T, Mathieu F, Guyonvarch A, Lebrihi A. Review of mycotoxin reduction in food and feed: from prevention in the field to detoxification by adsorption or transformation. Food Addit Contam - Part A Chem Anal Control Expo Risk Assess. 2011;28:1590-1609. https:// doi.org/10.1080/19440049.2011.595377

11. Blandino M, Haidukowski M, Pascale M, Plizzari L, Scudellari D, Reyneri A. Integrated strategies for the control of Fusarium head blight and deoxynivalenol contamination in winter wheat. F Crop Res. 2012;133:139-49. https://doi.org/10.1016/j.fcr.2012.04.004

12. Jouany JP. Methods for preventing, decontaminating and minimizing the toxicity of mycotoxins in feeds. Anim Feed Sci Technol. 2007;137:342-62. https://doi.org/10.1016/ j.anifeedsci.2007.06.009

13. Palazzini JM, Yerkovich N, Alberione E, Chiotta M, Chulze SN. An integrated dual strategy to control Fusarium graminearum sensu stricto by the biocontrol agent Streptomyces sp. RC $87 \mathrm{~B}$ under field conditions. Plant Gene. 2017;9:13-18. https:// doi.org/10.1016/j.plgene.2016.11.005

14. Salgado JD, Wallhead M, Madden LV, Paul PA. Grain harvesting strategies to minimize grain quality losses due to Fusarium Head 
Blight in wheat. Plant Dis. 2011;95:1448-57. https:// 27. Shude SPN. An integrated control strategy for managing Fusaridoi.org/10.1094/PDIS-04-11-0309

15. Shah L, Ali A, Yahya M, Zhu Y, Wang S, Si H, Rahman H, Ma C. Integrated control of fusarium head blight and deoxynivalenol mycotoxin in wheat. Plant Pathol. 2018;67:532-48. https:// doi.org/10.1111/ppa.12785

16. De Villiers $\mathrm{Cl}$. Glasshouse screening of CIMMYT wheat germplasm for Fusarium head blight response in South Africa. S Afr J Plant Soil. 2014;31:49-51. https:// doi.org/10.1080/02571862.2014.890752 um Head Blight of wheat using epiphytic yeasts and a plant defence inducer. MSc [dissertation]. Pietermaritzburg, South Africa: University of KwaZulu-Natal; 2020.

28. Zadoks JC, Chang TT, Konzak CF. A decimal code for growth stages of cereal. Weed Res. 1974;14:415-21. https:// doi.org/10.1111/j.1365-3180.1974.tb01084.x

29. Engle JS, Lipps PE, Mills D. Fusarium head blight severity scale for winter wheat. Bulletin AC-48-03, 2003. Extension Factsheet, Ohio State University.

17. Muthomi JW, Ndung'u JK, Gathumbi JK, Mutitu EW, Wagacha JM. The occurrence of Fusarium species and mycotoxins in Kenyan wheat. Crop Prot. 2008;27:1215-19. https://doi.org/10.1016/ j.cropro.2008.03.001

18. Dal Bello GM, Mónaco Cl, Simon M.R. Biological control of seedling blight of wheat caused by Fusarium graminearum with beneficial rhizosphere microorganisms. World J Microb Biot. 2002;18:627-36. https://doi.org/10.1023/A:1016898020810

19. Legrand F, Picot A, Cobo-Díaz JF, Chen W, Le Floch G. Challenges facing the biological control strategies for the management of Fusarium Head Blight of cereals caused by F. graminearum. Biol Control. 2017;113:26-38.

20. Javaid A, Afzal R. Shoaib A. Biological management of southern blight of chili by Penicillium oxalicum and leaves of Eucalyptus citriodora. Int J Agric Biol. 2020;23(1):93-102. https:// doi.org/10.17957/IJAB/15.1263

21. Ali A, Javaid A, Shoaib A, Khan IH. Effect of soil amendment with Chenopodium album dry biomass and two Trichoderma species on growth of chickpea var. Noor 2009 in Sclerotium rolfsii contaminated soil. Egypt. J Biol Pest Control. 2020;30:102. https:// doi.org/10.1186/s41938-020-00305-1

22. Javaid A, Ali A, Shoaib A, Khan IH. Alleviating stress of Sclertium rolfsii on growth of chickpea var. Bhakkar-2011 by Trichoderma harzianum and T. viride. J Anim Plant Sci. 2020;31(6): https:// doi.org/10.36899/JAPS.2021.6.0378

23. Wegulo SN, Bockus WW, Nopsa JH, De Wolf ED, Eskridge KM, Peiris KHS, Dowell FE. Effects of Integrating Cultivar Resistance and Fungicide Application on Fusarium Head Blight and Deoxynivalenol in Winter Wheat. Plant Dis. 2010;95:554-60. https:// doi.org/10.1094/PDIS-07-10-0495

24. Schisler DA, Boehm MJ, Paul PA, Rooney AP, Dunlap CA. Reduction of Fusarium head blight using prothioconazole and prothioconazole-tolerant variants of the Fusarium head blight antagonist Cryptococcus flavescens $\mathrm{OH}$ 182.9. Biol Control 2015;86:3645. https://doi.org/10.1016/j.biocontrol.2015.04.002

25. Schisler DA, Slininger PJ, Boehm MJ, Paul PA. Co-culture of yeast antagonists of Fusarium head blight and their effect on disease development in wheat. Plant Pathol J. 2011;10:128-37. https:// doi.org /10.3923/ppj.2011.128.137

26. Zhang S, Schisler DA, Boehm MJ, Slininger PJ. Utilization of chemical inducers of resistance and Cryptococcus flavescens $\mathrm{OH}$ 182.9 to reduce Fusarium head blight under greenhouse conditions. Biol Control. 2007;42:308-15. https://doi.org/10.1016/ j.biocontrol.2007.05.020

30. Trass M, Misa A, Rivers B. A rapid extraction and screening method for mycotoxins from cereal products using QuEChERS and LC/ MS/MS. Phenomenex Technical Note (TN0071). [Internet] 2019 [cited 30 June 2019]. Available from: https:// www.phenomenex.com/ViewDocument? id=a+rapid+extraction+and+screening+method+for+mycotoxins +from+cereal+products+using+quechers+and+lc_ms_ms+(tn0071)\&fsr=1

31. Shaner G, Finney RE. The effect of nitrogen fertilization on the expression of slow-mildewing resistance in Knox wheat. Phytopathology 1977;67:1051-56. https://doi.org/10.1094/PHYTO-671051

32. SAS Institute Inc. SAS ${ }^{\circ} 9.4$ System Operations: Reference, Fifth Edition. Cary, NC: SAS Institute Inc. [Internet] 2016 [cited 20194 Aug] Available from: https://citeseerx.ist.psu.edu/viewdoc/ download?doi=10.1.1.353.6870\&rep=rep1\&type=pdf

33. Van der Plank JE. Plant diseases: Epidemics and control. New York: Academic Press;1963. https://doi.org/10.1097/00010694196410000-00018.

34. Yousseff K, Roberto SR, Colombo RC, Canteri MG, Abd-Elsalam KA. Acibenzolar-S-Methyl against Botrytis mold on table grapes in vitro and in vivo. Agron Sci Biotechnol. 2019;5(1):52-61. https:// doi.org/10.33158/ASB.2019v5i1p52

35. Mejia C, Farfan D, Montana JS, Restrepo S, Jimenez P, Danies G, Rodríguez-Bocanegra MX. Acibenzolar-S-Methyl induces protection against the vascular wilt pathogen Fusarium oxysporum in cape gooseberry (Physalis peruviana L.). J Plant Dis Prot. 2021:128:449-56. https://doi.org/10.1007/s41348-021-00427-0

36. Khan NI, Schisler DA, Boehm MJ, Slininger PJ, Bothast RJ. Selection and evaluation of microorganisms for biocontrol of Fusarium head blight of wheat incited by Gibberella zeae. Plant Dis. 2001;85:1253-58. https://doi.org/10.1094/PDIS.2001.85.12.1253 